\title{
The study of toxicity effects of biosynthesized silver nanoparticles using Veronica officinalis extract
}

\author{
R. Dobrucka ${ }^{1} \cdot$ M. Szymanski ${ }^{2} \cdot$ R. Przekop ${ }^{2}$
}

Received: 16 January 2019 / Revised: 9 June 2019 / Accepted: 17 June 2019 / Published online: 24 June 2019

(c) The Author(s) 2019

\begin{abstract}
The main objective of the work was to assess the phytotoxicity of silver nanoparticles synthesized biologically using Veronica officinalis extract. The silver nanoparticles obtained by means of biological synthesis were characterized by UV-vis spectrophotometry (UV-VIS), transmission electron microscopy, scanning electron microscopy and atomic force microscopy (AFM). In order to assess the presence of biologically active compounds in V. officinalis extract, Fourier-transform infrared spectroscopy was used. AFM measurements indicated that the size of the obtained silver nanoparticles was about $15 \mathrm{~nm}$. The phytotoxicity studies showed that biosynthesized silver nanoparticles did not exhibit any toxic effect throughout the range of concentrations examined during the study (0.0009-0.0675), both as regards Linum flavum and Lepidium sativum seeds.
\end{abstract}

Keywords Phytotoxicity $\cdot$ Silver nanoparticles $\cdot$ Veronica officinalis

\section{Introduction}

Nanotechnology belongs to the fastest growing science in the world, and its products are applied in many branches of industry. Nanomaterials can solve challenges related to water treatment, catalysis and medicine-both technological and environmental ones (Ajitha et al. 2015). One interesting solution offered by nanotechnology involves metal nanoparticles, which have unique physicochemical characteristics that can influence material properties and enable the utilization of metal nanoparticles in many consumer products and industrial technologies (Johari et al. 2018). The methods for producing metal nanoparticles include, among others, sol-gel, electrochemical or chemical reduction method (Parida et al. 2011).

Editorial responsibility: M. Abbaspour.

R. Dobrucka

renata.dobrucka@ue.poznan.pl

1 Department of Industrial Products Quality and Ecology, Faculty of Commodity Science, Poznan University of Economics and Business, al. Niepodległosci 10, 61-875 Poznan, Poland

2 Centre for Advanced Technologies, Adam Mickiewicz University in Poznań, ul. Umultowska 89c, 61-614 Poznan, Poland
A great number of scientists have focused on silver nanoparticles, which are applied the most widely due to their well-known antibacterial and antifungal effects, as well as their plasmonic and opto-electrical properties (Pokhrel and Dubey 2013). Silver nanoparticles are applied in numerous products, such as food packaging, cosmetics or medical devices (Saqib and Rahim 2016). The growing production and exploitation of metal nanoparticles raise concerns about their release to the atmosphere, as such release may have a negative impact on the environment, and thus also on human health (Cvjetko et al. 2018). The current world literature shows that plants can absorb metal nanoparticles, which leads to their accumulation in the food chain. This, in turn, makes it possible for them to reach the consumer (Pittol et al. 2017). Several studies demonstrated many toxic effects of metal nanoparticles on fruiting, flowering and other physiological processes, which may be dangerous for the sustainable agriculture worldwide (Tripathi et al. 2017).

Some indirect effects include the release of toxic metal ions or production of reactive forms of oxygen (Navarro et al. 2008). Prokaryotes have a limited ability to absorb nanoparticles, which, in theory, protects them from the toxic effect of some nanomaterials. Eukaryotes are more susceptible to penetration by nanomaterials. In the case of eukaryotes, nanomaterials can penetrate into cells as a result of diffusion through cell membranes, endocytosis 
(pinocytosis, phagocytosis, receptor-mediated endocytosis) or adhesion. Inside cells, nanomaterials may interact with the respective organelles, which may interfere with various metabolic processes. Many studies have demonstrated the toxic effects of silver nanoparticles on bacteria, mammals, animals, cells and plants. Researchers claim that toxicity stems from, among others, a strong affinity for thiol groups. Many studies have demonstrated the potential toxic effects of silver nanoparticles on marine species at different trophic levels, including algae (Skeletonema costatum and Dunaliella tertiolecta), cnidaria (Aurelia aurita), crustaceans (Artemia salina and Amphibaanus amphitrite), echinoderms (Paracentrotus lividus), sea urchin (Paracentrotus lividus) and oysters (Johari et al. 2018). The studies carried out by KhosraviKatuli et al. (2018) showed negative effects of silver on different aspects of the health of juvenile common carp. Certain works in the literature present studies concerning the phytotoxicity of metal nanoparticles. One example is the work of Lin and Xing (2007), who assessed the phytotoxicity of five types of multiwalled NPs (MWCNT, $\mathrm{Al}, \mathrm{Al}_{2} \mathrm{O}_{3}, \mathrm{Zn}$ and $\mathrm{ZnO}$ ) on seed germination and seedling root growth in six higher plant species. In their work, Kumari et al. (2009) stated that Ag nanoparticles inhibited the growth of terrestrial plants Allium cepa. Pereira et al. (2018) assessed the phytotoxicity of silver nanoparticles to Lemna minor. Ma et al. (2010) examined the toxic effects of different sizes of AgNPs (20-80 nm) on Arabidopsis thaliana seedlings, and they observed an increase in toxicity after increasing the concentration of AgNPs. Al-Huqail et al. (2018) examined the morphological and anatomical changes in Lupinus termis leaves in response to different concentrations of green AgNPs. The authors of this work assessed the phytotoxic activity of silver nanoparticles biosynthesized with the use of Veronica officinalis extract against Lepidium sativum and Linum flavum seeds. It was very important to check whether biologically synthesized nanosilver had a toxic effect on the seeds used in the study because the majority of phytotoxicity studies reported so far have used chemically synthesized nanoparticles. The obtained results of the study can play a significant role in identifying various environmental risks associated with biologically synthesized silver nanoparticles.

\section{Materials and methods}

\section{Materials}

The study was carried out with the use of chemicals bought from Sigma-Aldrich (Poland). The seeds used in the study were of L. sativum (BIO Garden cress-Certified ecological seeds), L. flavum (Producer: Bio Planet). Aerosil 200 (Evonik Resource Efficiency GmbH; CAS No. 112945-52-5).

\section{Preparation of silver nanoparticles}

Veronica officinalis was collected from Wielkopolska region (Poland). To prepare the extract, $2 \mathrm{~g}$ of $V$. officinalis in powdered form was mixed with $250 \mathrm{ml}$ of an aqueous solution and vigorous stirring for $50 \mathrm{~min}$ at the temperature of $80^{\circ} \mathrm{C}$. The obtained $V$. officinalis extract was used immediately after filtration through Whatman's No. 1 filter paper. In order to produce nanosilver, a typical synthesis procedure is carried out (Al-Huqail et al. 2018; Raj et al. 2018), using the $\left.(1 \mathrm{mM} \mathrm{AgNO})_{3}\right)$ solution. The synthesis of AgNPs was carried out as follows: The extract was combined with $\mathrm{AgNO}_{3}$, in equal amounts. Next, the prepared solution was stirred at $60{ }^{\circ} \mathrm{C}$ for $24 \mathrm{~h}$.

\section{Characterization of silver nanoparticles}

To study the UV absorption spectra, spectrophotometer Cary E 500 was used, with a quartz cell length with $10 \mathrm{~mm}$ of optical path, in the range of $300 \mathrm{~nm}-800 \mathrm{~nm}$. To analyze the Fourier-transform infrared spectroscopy (FTIR) spectra of the prepared samples, PerkinElmer Spectrum 1000 was used. The obtained biosynthesized silver nanoparticles were characterized using an atomic force microscope (Agilent 5500), transmission electron microscope JEOL JEM 1200 EXII $(200 \mathrm{kV})$ and scanning electron microscope (HR SEM) Helios NanoLab 660 (FEI).

\section{Phytotoxicity of silver nanoparticles}

To verify whether the prepared biosynthesized silver nanoparticles, the $V$. officinalis (herba) extract and $\mathrm{AgNO}_{3}$ had any phytotoxic properties, the stock solution was diluted to obtain the following concentrations: $V$. officinalis extract (for flax seeds: $0.085 ; 0.170 ; 0.340 ; 0.425 ; 0.850$; $1.275 ; 1.700 ; 1.913 \mathrm{mg} / \mathrm{ml}$; for garden cress seeds: 0.088 ; $0.175 ; 0.340 ; 0.680 ; 1.750 ; 3.500 ; 4.375 ; 8.750 \mathrm{mg} / \mathrm{ml}$ ); $\mathrm{AgNO}_{3}$ solution (for flax seeds: $0.0017 ; 0.0034 ; 0.0044$; $0.0068 ; 0.0085 ; 0.0091 ; 0.0136 ; 0.0170 \mathrm{mg} / \mathrm{ml}$; for garden cress seeds: $0.0017 ; 0.0034 ; 0.0044 ; 0.0068 ; 0.0085$; $0.0091 ; 0.0136 ; 0.0170 \mathrm{mg} / \mathrm{ml})$; and silver nanoparticles (for flax seeds: $0.0009 ; 0.0027 ; 0.0090 ; 0.0180 ; 0.0360$; $0.0225 ; 0.0450 ; 0.0675 \mathrm{mg} / \mathrm{ml}$; for garden cress seeds: $0.0009 ; 0.0027 ; 0.0090 ; 0.0180 ; 0.0360 ; 0.0225 ; 0.0450$; $0.0675 \mathrm{mg} / \mathrm{ml}$ ). Then, $2.0 \mathrm{~g}$ of Aerosil 200 was weighed on a Petri dish and combined with $20 \mathrm{ml}$ of each dilution 
of the stock solution. The mixtures were stirred until they achieved a uniform consistency, and their surface was levelled. Demineralized water was added to the weighed Aerosil as a reference sample. Then, 20 flax seeds and 20 garden cress seeds were transferred on the substrate. The samples were subjected to incubation at $23.0^{\circ} \mathrm{C}, 72 \mathrm{~h}$ (garden cress) and $120 \mathrm{~h}$ (flax). When the period of incubation ended, the dishes were taken out in order to measure the growth of plants.

\section{Results and discussion}

\section{UV-Visible absorption}

Figure 1 shows the UV-visible spectra related to silver nanoparticles that were biosynthesized with the use of $V$. officinalis extract. The optical absorption spectra related to AgNPs (silver nanoparticles) that were biosynthesized with the use of $V$. officinalis extract were recorded at the range of $800-350 \mathrm{~nm}$. After stirring for $24 \mathrm{~h}$, a peak was observed at $521 \mathrm{~nm}$. The yellow-brown color of the samples and the absorption peak at $521 \mathrm{~nm}$ stem from the excitation of surface plasmon vibrations in the silver nanoparticles.

\section{FTIR analysis}

The FTIR spectra related to silver nanoparticles that were biosynthesized with the use of $V$. officinalis extract showed the major absorption bands at $3322 \mathrm{~cm}^{-1}, 2113 \mathrm{~cm}^{-1}$, $1634 \mathrm{~cm}^{-1}, 424 \mathrm{~cm}^{-1}, 410 \mathrm{~cm}^{-1}, 402 \mathrm{~cm}^{-1}$ and $383 \mathrm{~cm}^{-1}$ (Fig. 2). The peak which appeared at $3322 \mathrm{~cm}^{-1}$ is related to intramolecular hydrogen-bonded $\mathrm{OH}$. The peak which appeared at $2113 \mathrm{~cm}^{-1}$ may indicate the presence of an alkyne group. The band at $1634 \mathrm{~cm}^{-1}$, which is the most intense, depicts $\mathrm{C}=\mathrm{O}$ vibrations, which are characteristic of the flavonoid structure. The absorption bands at $424 \mathrm{~cm}^{-1}$, $410 \mathrm{~cm}^{-1}, 402 \mathrm{~cm}^{-1}$ and $333 \mathrm{~cm}^{-1}$ indicated the formation of metal-biomolecules present in the extract. The conducted studies confirm the presence of functional groups that form part of active compounds in $V$. officinalis extract, such as iridoid glycosides, mainly aucubin, as well as mannitol, $\beta$-sitosterol, phenolic acids, tannins, flavonoids and saponins (Gründemann et al. 2013).

\section{SEM and TEM analysis}

Figure 3 presents the SEM and TEM images of silver nanoparticles that were biosynthesized with the use of $V$. officinalis extract. The SEM images at magnification (A) 5000×, (B) $10,000 \times$, (C) $30,000 \times$ and (D) $100,000 \times$ confirmed that the size of the silver nanoparticles biosynthesized using $V$. officinalis extract was about $15 \mathrm{~nm}$. In some places, nanoparticles formed agglomerates of about $40 \mathrm{~nm}$. The transmission electron microscopy (TEM) images also showed that the biosynthesized $\mathrm{Ag}$ nanoparticles were spherical in shape and about $15 \mathrm{~nm}$ in size. Figure $3 \mathrm{e}, \mathrm{f}$ shows the TEM images at $100,000 \times$ magnifications.

\section{AFM analysis}

Figure 4 presents the AFM image of silver nanoparticles that were synthesized with the use of $V$. officinalis extract with (A) the topography $10 \mu \mathrm{m} \times 10 \mu \mathrm{m}$, (B) the topography $3 \mu \mathrm{m} \times 3 \mu \mathrm{m},(\mathrm{C})$ the topography $3 \mu \mathrm{m} \times 3 \mu \mathrm{m}$ with the profile and (D) the profile of nanoparticles.
Fig. 1 UV-visible spectra of biosynthesized silver nanoparticles using $V$. officinalis extract

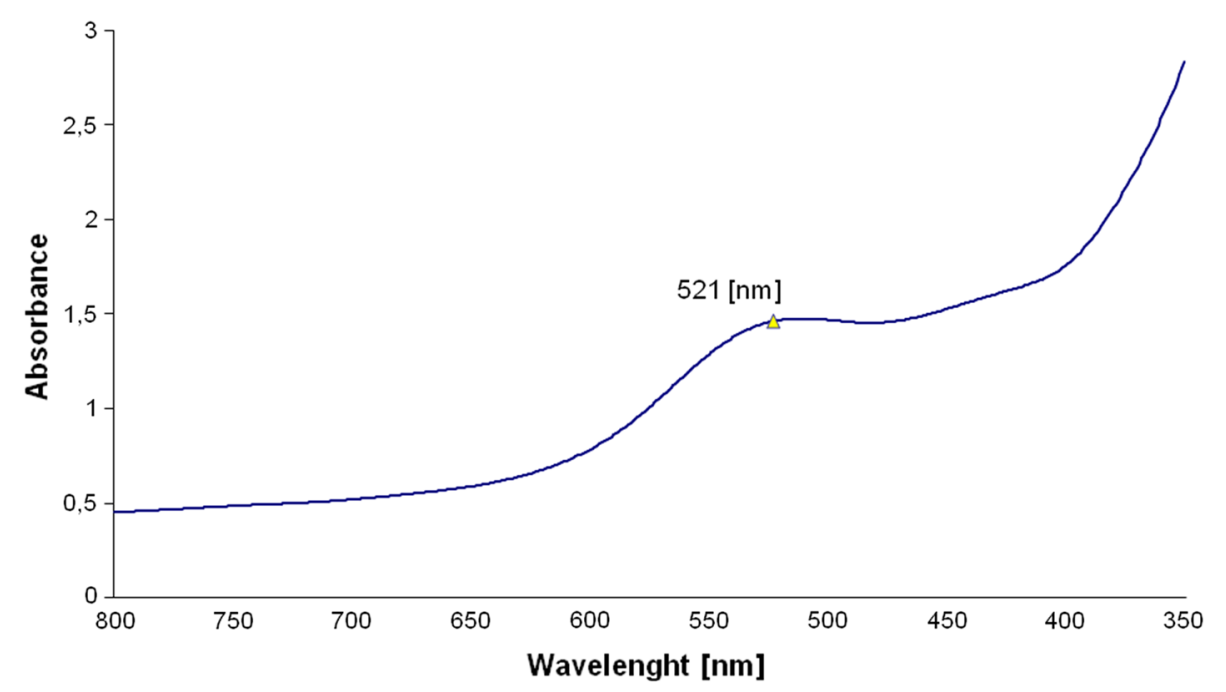

Springer 


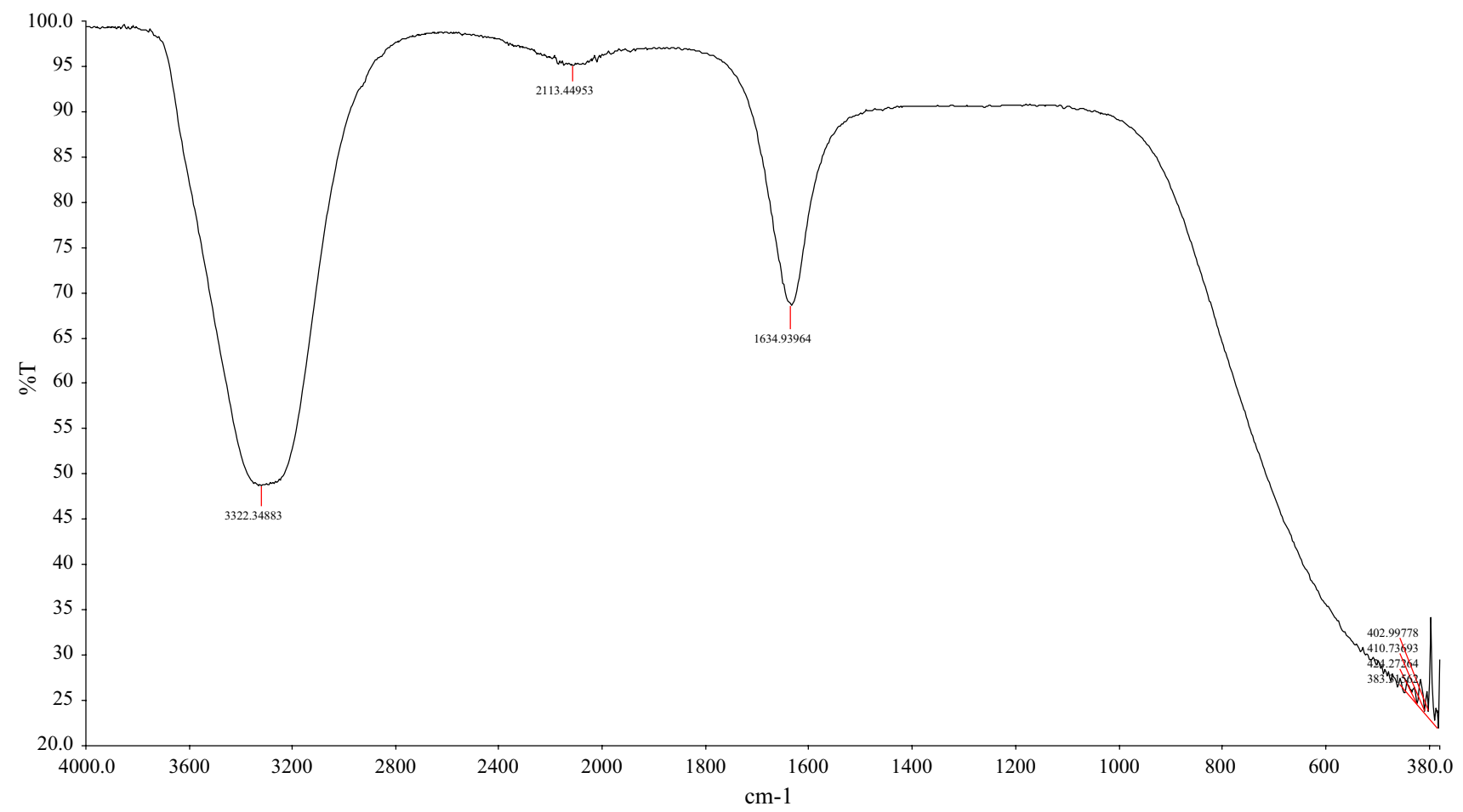

Fig. 2 FTIR spectra of biosynthesized silver nanoparticles using $V$. officinalis extract

The examination confirmed the sizes of nanoparticles obtained from previous measurements: The observed nanoparticles were about $15 \mathrm{~nm}$. Like SEM (scanning electron microscopy), the AFM image also confirmed the presence of agglomerated nanoparticles that were about $40 \mathrm{~nm}$ in size.

\section{Determination of the inhibitory concentration $50 \%$ (IC50)}

Toxic effects can manifest themselves at different stages of plant development, depending on the conditions in which the plants are grown as well as their systematic classification. The activity of some substances is limited to the place in which they have been absorbed, i.e., it is only local. There are also substances that act systemicallyafter absorption, they move inside the plant. Some compounds are toxic only after they are absorbed by the leaves, the other-the root system, and some will exhibit toxic effects regardless of the manner in which they were taken in. There are many scientific analyses devoted to the impact that silver nanoparticles exercise on various plant species. This work has assessed the phytotoxicity of biosynthesized silver nanoparticles, the prepared extract of $V$. officinalis and $\mathrm{AgNO}_{3}$. The measured values of plant growth or its inhibition, compared to the control sample, served as the basis for creating the chart that shows the dependence of growth activity $(\mathrm{Ga})\{100 *$ (growth length of a respective seed - average length of the control sample)/average length of the control sample\} on concentration (C). Figure 5 shows the chart that presents the dependence of growth activity on concentration for biosynthesized silver nanoparticles (garden cress seeds).

In toxicity studies, it is important to determine the IC50 coefficient, which means the concentration of a toxic substance inhibits growth by a certain percent $(50 \%)$, compared to the control sample. The IC50 coefficient (i.e., the concentration which inhibits the growth of the test plant by $50 \%$ ) for $V$. officinalis extract as regards flax seeds was calculated on the basis of the equation: $\mathrm{Ga}=a^{*} \ln (C) b$. The IC50 coefficient of biosynthesized silver nanoparticles could not be determined because the solutions did not exhibit a sufficient toxic effect on the studied range of concentrations. The authors of the study determined a nominal equation $y=\mathrm{a} x^{2}+\mathrm{b} x+c$ with a high $R^{2}$ correlation coefficient.

The experimental data as well as the squared correlation coefficient served as the basis for determining the equations presented in Table 1. For biosynthesized silver nanoparticles, the $R^{2}$ correlation coefficient was, respectively, 0.8145 (L. flavum) and 0.8739 (L. sativum). For $\mathrm{AgNO}_{3}$, it was 0.9936 (L. flavum) and 0.9942 (L. sativum). The $R^{2}$ 
Fig. 3 SEM images of biosynthesized silver nanoparticles using $V$. officinalis extract at magnification $\mathbf{a} \times 5000, \mathrm{~b}$ $\times 10000, \mathbf{c} \times 30000, \mathbf{d} \times 100,000$ and TEM images $(\mathbf{e}, \mathbf{f})$ at $\times 100,000$

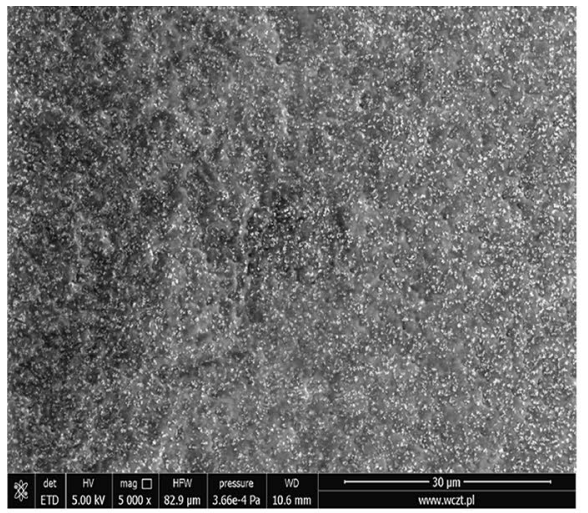

(A)

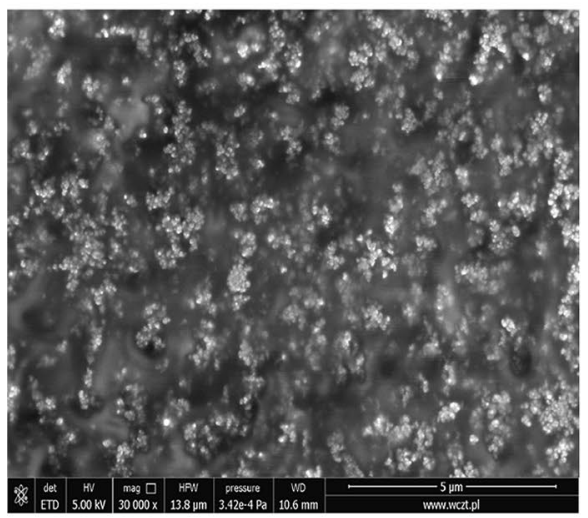

(C)

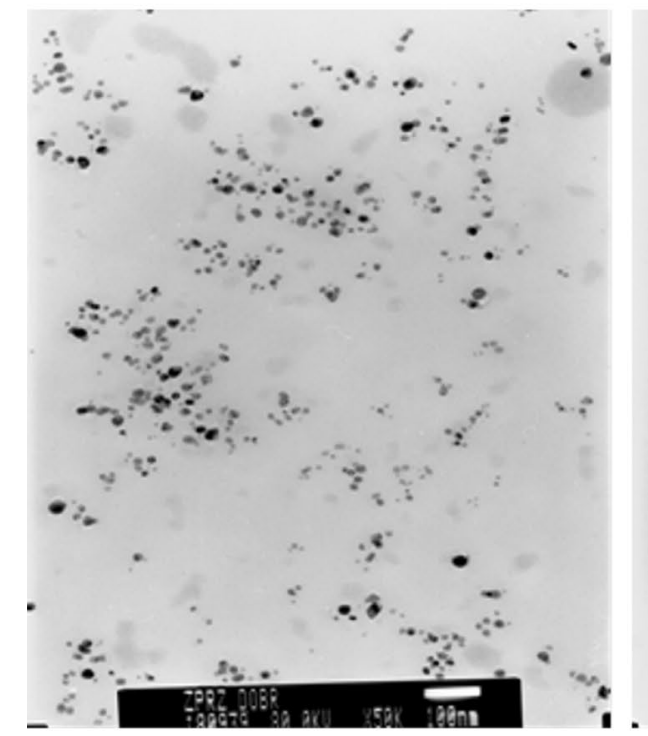

(E)

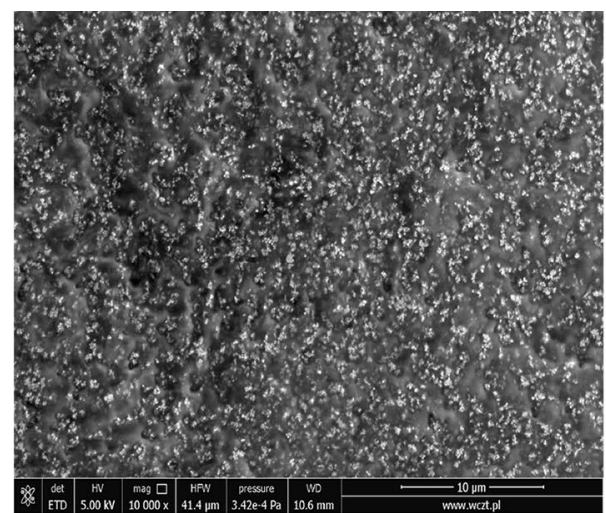

(B)

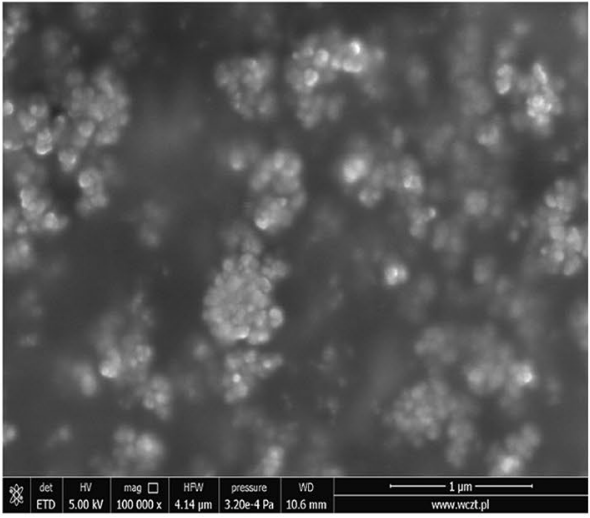

(D)

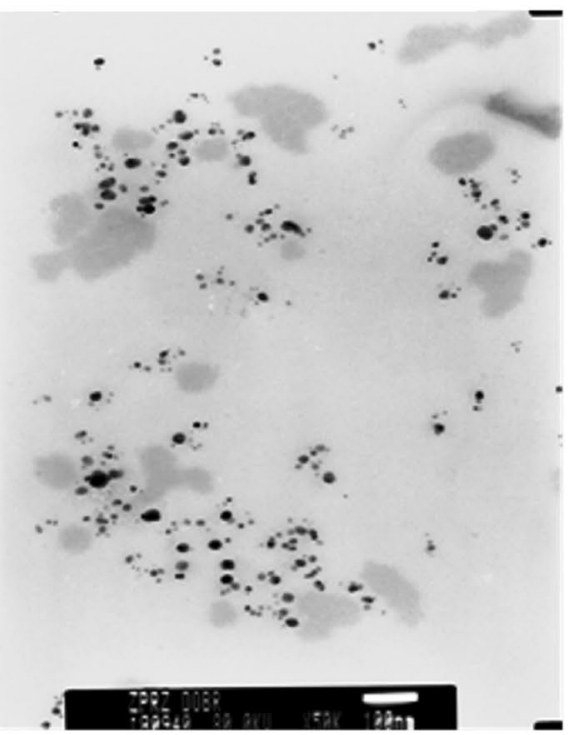

(F) correlation coefficient for Veronica officinalis extract was 0.9648 (L. flavum) and 0.9674 (L. sativum). The phytotoxicity of $V$. officinalis extract, $\mathrm{AgNO}_{3}$ solution and silver nanoparticle solution to garden cress and flax seeds, expressed by means of the IC50 coefficient, is specified in Table 2. Biosynthesized silver nanoparticles using $V$. officinalis extract did not show any toxic effect throughout the range of concentrations assessed during the study, both 


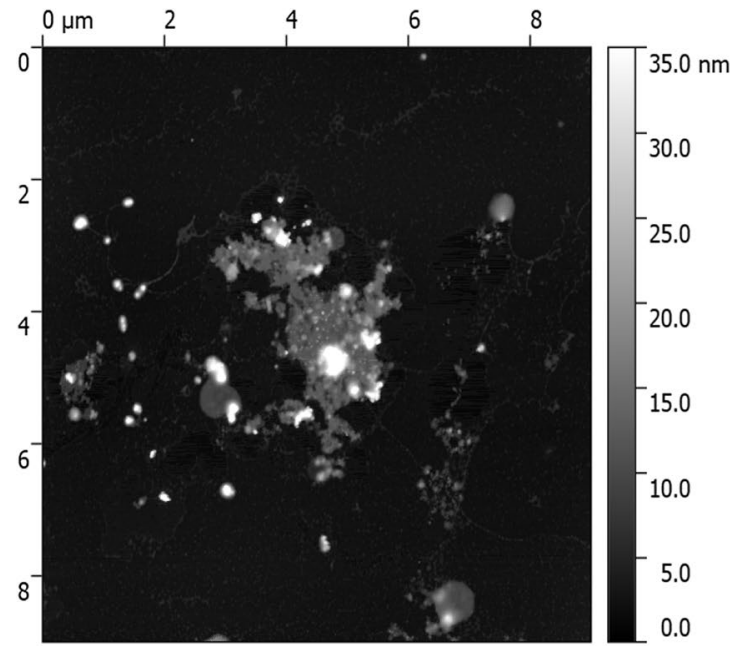

(A)

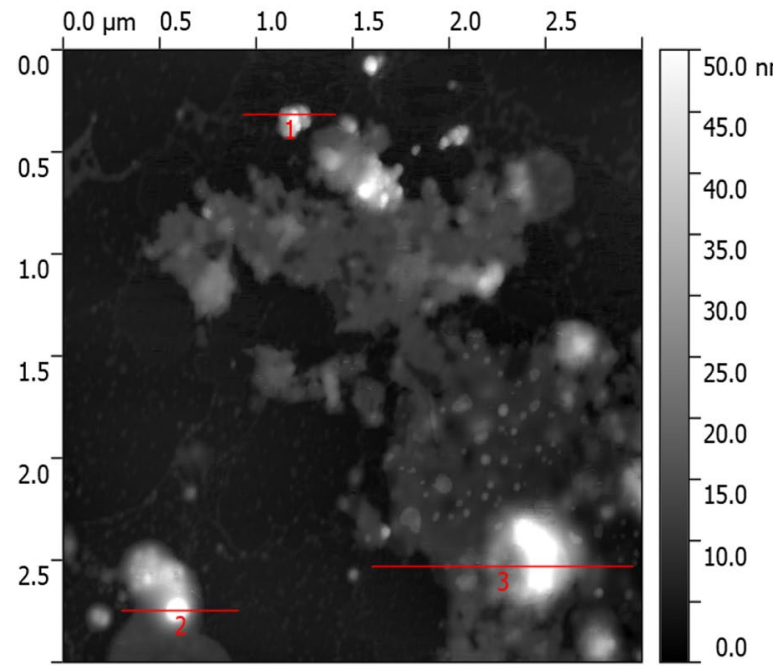

(C)

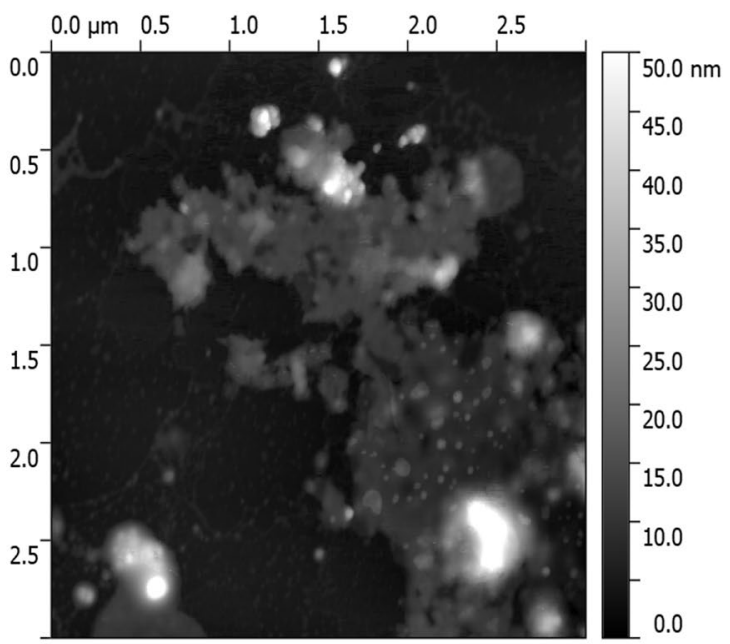

(B)

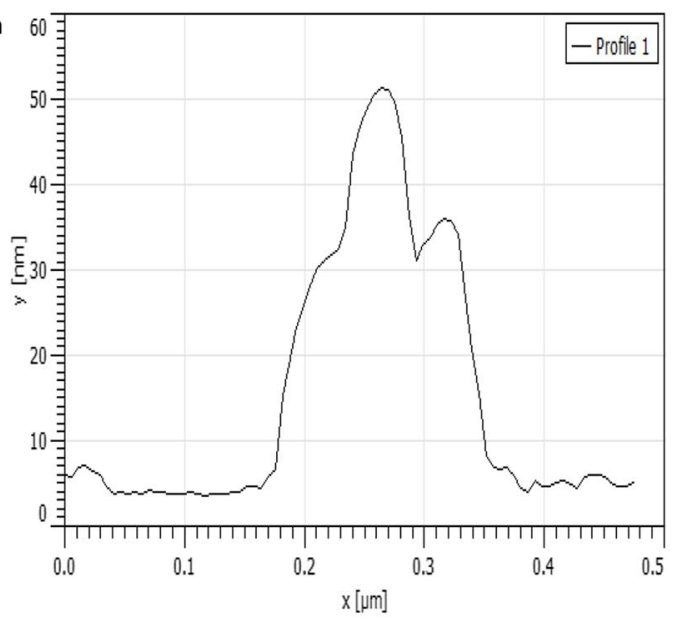

(D)

Fig. 4 AFM image of biosynthesized silver nanoparticles using $V$. officinalis extract with a the topography $10 \mu \mathrm{m} \times 10 \mu \mathrm{m}$, b the topography $3 \mu \mathrm{m} \times 3 \mu \mathrm{m}$, c the topography $3 \mu \mathrm{m} \times 3 \mu \mathrm{m}$ with the profile and $\mathbf{d}$ the profile of nanoparticles

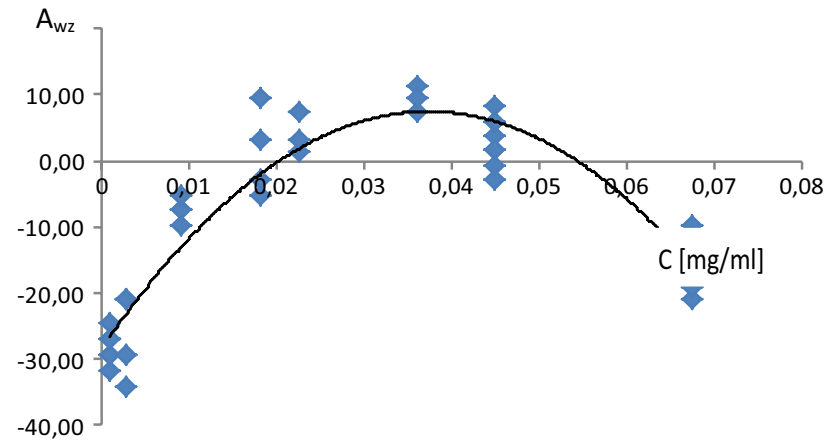

Fig. 5 The chart that presents the dependence of growth activity on concentration for biosynthesized silver nanoparticles (garden cress seeds) as regards $L$. flavum seeds and $L$. sativum seeds. Figure 6 presents the measurement of growth length of garden cress seeds for the following concentrations of silver nanoparticles: (A) $0.0009 \mathrm{mg} / \mathrm{ml}$, (B) $0.0090 \mathrm{mg} / \mathrm{ml}$, (C) 0.0225 (D) and $0.045 \mathrm{mg} / \mathrm{ml}$.

As regards silver nitrate, the determined IC50 coefficient was $0.0171 \mathrm{mg} / \mathrm{ml}$ for L. flavum and $0.0125 \mathrm{mg} / \mathrm{ml}$ for L. sativum. The $\mathrm{AgNO}_{3}$ solution showed an inhibitory effect at the entire range of the examined concentrations. The conducted analyses led to a conclusion that silver nitrate was the most phytotoxic solution to both flax and garden cress seeds. The extract of $V$. officinalis, which was used in the work, had some interesting characteristics. Figure 7 presents samples with test flax 
Table 1 Curve equations for the respective measurements determined on the basis of experimental data and the squared correlation coefficient

\begin{tabular}{clll}
\hline & Plant & Curve equation & $\begin{array}{l}\text { Correlation } \\
\text { coefficient } R^{2}\end{array}$ \\
\hline Veronica officinalis & Linum flavum & $y=64.277 \ln (x)+51.53$ & 0.9648 \\
extract & Lepidium sativum & $y=2.2193 x^{2}-29.021 x+4.1294$ & 0.9674 \\
$\mathrm{AgNO}_{3}$ & Linum flavum & $y=5848.8 x-49.816$ & 0.9936 \\
& Lepidium sativum & $y=6566.4 x-31.968$ & 0.9942 \\
Biosynthesized sil- & Linum flavum & $y=5953.1 x^{2}-206.5 x-23.944$ & 0.8145 \\
ver nanoparticles & Lepidium sativum & $y=-25644 x^{2}+1912.6 x-28.181$ & 0.8739 \\
\hline
\end{tabular}

Table 2 IC50 coefficient values determined for the tested samples

\begin{tabular}{llll}
\hline & $\begin{array}{l}\text { Veronica } \\
\text { officinalis } \\
\text { extract }\end{array}$ & $\begin{array}{l}\text { Solution } \\
\text { of } \mathrm{AgNO}_{3}\end{array}$ & $\begin{array}{l}\text { Biosynthesized } \\
\text { silver nanopar- } \\
\text { ticles }\end{array}$ \\
\hline $\begin{array}{l}\mathrm{IC}_{50} \text { for L. flavum }(\mathrm{mg} / \\
\mathrm{ml})\end{array}$ & 3.3927 & 0.0171 & $\mathrm{nt}$ \\
$\begin{array}{l}\mathrm{IC}_{50} \text { for L. sativum }(\mathrm{mg} / \mathrm{nt} \\
\mathrm{ml})\end{array}$ & 0.0125 & $\mathrm{nt}$ \\
\hline
\end{tabular}

$n t$ non-toxic in the range of concentration

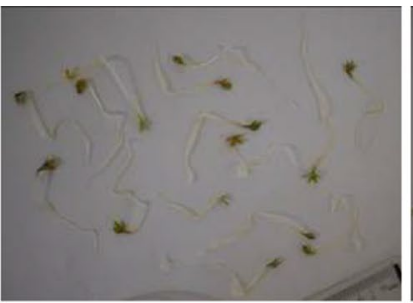

(A)

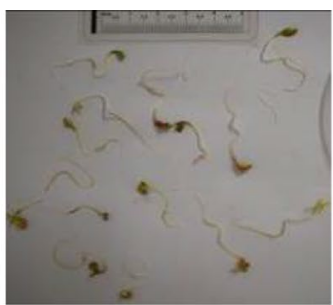

(B)

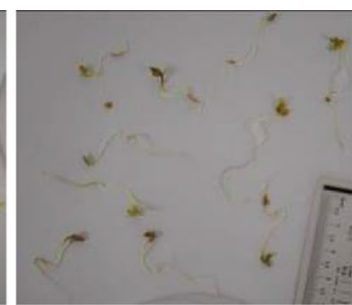

(C)

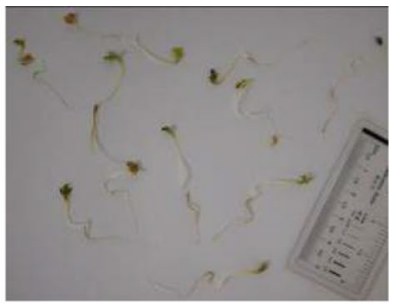

(D)

Fig. 6 The measurement of growth length of garden cress seeds for the following concentrations of silver nanoparticles: a $0.0009 \mathrm{mg} / \mathrm{ml}$, b $0.0090 \mathrm{mg} / \mathrm{ml}, \mathbf{c} 0.0225$ and $\mathbf{d} 0.045 \mathrm{mg} / \mathrm{ml}$

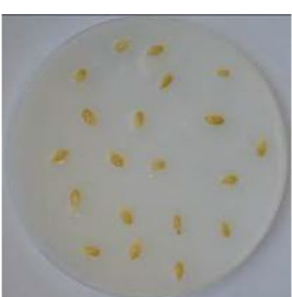

(A)

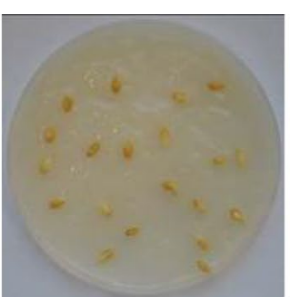

(B)

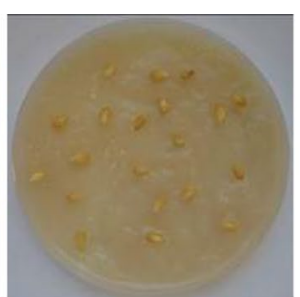

(C)

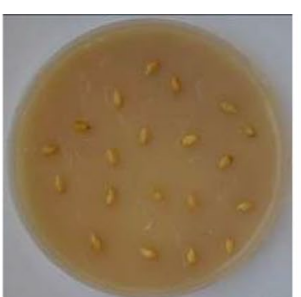

(D)

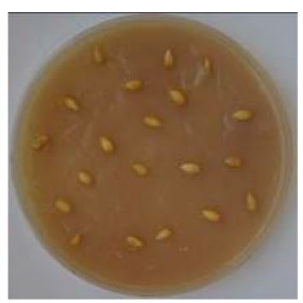

(E)

Fig. 7 The samples with test flax seeds before the examination for the following concentrations of $V$. officinalis extract: a $0.017 \mathrm{mg} / \mathrm{ml}$, b $0.425 \mathrm{mg} / \mathrm{ml}$, c $0.850 \mathrm{mg} / \mathrm{ml}$ and $\mathbf{d} 1.275 \mathrm{mg} / \mathrm{ml} ;$ e $1.913 \mathrm{mg} / \mathrm{ml}$ 
with an aqueous solution of any chemical compound or an extract, for example, of plant materials, will make it possible to determine whether or not the assessed solution or extract is toxic to a given plant. When demineralized water is replaced with an aqueous solution of any chemical compound or, for instance, plant material extract, it is possible to verify whether such a solution or extract is toxic to a given plant. A number of dilutions will allow the calculation of the IC50 coefficient. The correlation coefficients $\left(R^{2}\right)$ for growth activity charts from concentration $A_{\mathrm{wz}}=f(C)$ within the range from 0.8145 to 0.9942 indicate that the method for assessing phytotoxicity has been developed properly. Lower values of correlation coefficients for charts based on biosynthesized Ag nanoparticles may be the result of lower solution stability or nanoparticle agglomerations that may form in the analyzed conditions. Charts related to a stable $\mathrm{AgNO}_{3}$ solution were characterized by high $R^{2}$ coefficients.

As regards silver nanoparticles, at first, they stimulated the growth of garden cress. Next, the growth was hindered, and later it was stimulated once again. The solution of silver nanoparticles stimulated flax growth at all tested concentrations. Those results demonstrate that silver nanoparticles synthesized biologically using $V$. officinalis extract are nontoxic. They also suggest that flax germination is somehow resistant to the negative impact of silver nanoparticles. Flax germination was shown to undergo no significant changes due to any type of treatment, regardless of concentrations (El-Temsah and Joner, 2012). On the basis of those results, it can be concluded that flax seedlings have a higher limit of toxicity.

There are no doubts that the method of producing nanoparticles impacts their toxicity. Studies carried out by Gopinath et al.'s (2016) research group proved that the nanoparticles of pure $\mathrm{TiO}_{2}$, Au and Pt as well as doped $\mathrm{TiO}_{2}$ obtained from biological synthesis with the use of Terminalia arjuna bark are not toxic. Patil et al. (2012) showed that silver nanoparticles obtained with the use of Pergularia daemia are not toxic to P. reticulata fish. Shanthi et al. (2016) obtained nanosilver using probiotic bacteria-Bacillus licheniformis. The scientists based on research observed that silver nanoparticles produced with the use of bacteria were less toxic to fresh crustaceansCeriodaphnia cornuta $(50 \mathrm{mg} / \mathrm{ml})$ than silver nitrate (22 $\mathrm{mg} / \mathrm{ml}$ ). Similar results were obtained by Zahir and Rahuman (2012), who assessed the toxicity of nanosilver produced with the use of Euphorbia prostata leaf extract. The authors examined certain particles and extracts made with the use of different solvents and assessed their toxic effects on Daphnia magna and Ceriodaphnia dubia. They observed no toxicity or side effects after the exposure to the prepared extracts and the synthesized nanosilver. Tripathi et al. (2017) showed that $\mathrm{AgNO}_{3}$ is more toxic than silver nanoparticles, while potential risks of both forms are critical to the growth and development of Cucumis sativus. As shown by Tripathi et al. (2017) in their research, silver nanoparticles inhibit the growth and photosynthesis of Pisum sativum seedlings by enhancing oxidative stress and altering the antioxidant defense system. The shape of metal nanoparticles can also affect their toxic properties. According to (George et al. 2012), silver nanoplates induced more serious acute toxic effects on zebrafish embryos than nanosized silver spheres and nanosized silver wires. Another significant factor is connected with the occurrence of metal nanoparticles and their abilities in terms of aggregation. One of the studies that proved this was the study conducted by $\mathrm{Ng}$ et al. (2015). According to them, the low toxicity of $\mathrm{SnO}_{2}$ oxides, aluminum oxide and $\mathrm{In}_{2} \mathrm{O}_{3}$ could be caused by their tendency to create bigger aggregates in the solution, as a result of which the interaction between metal nanoparticles and the cell walls of the test organisms is reduced. On the other hand (Thuesombat et al., 2014), as larger nanoparticles have a greater ability to penetrate plant tissues and be transported by them, they are capable of affecting plants in a negative manner. According to Stoehr et al. (2011), wires of AgNPs (100-160 nm) significantly reduced cell viability and increased LDH release from alveolar epithelial cells, whereas spherical AgNPs $(30 \mathrm{~nm})$ had no effect.

\section{Conclusion}

Contact with materials in the nanoscale may result in penetration of various kinds of cells, which is a very important potential consequence. Nanoparticles exercise a direct impact on algae, plants and fungi by entering into redox reactions with organic particles, which disturbs the processes of photosynthesis and respiration. Cellulose cell walls of algae and higher plants, as well as chitin walls of fungi, have small pores with the diameter of 5-20 nm, and nanoparticles may induce creation of larger pores. After penetrating cell wall, nanoparticles encounter the cytoplasmic membrane. The membrane becomes convex, encloses nanoparticles in bubbles and pulls them in the cell. The majority of the reported phytotoxicity studies used nanoparticles synthesized by means of chemical methods. For this reason, this work examined the influence of silver nanoparticles, $\mathrm{AgNO}_{3}$ and Veronica officinalis extract on the seeds of $L$. sativum and L. flavum. 
The results confirmed that biosynthesized AgNPs using $V$. officinalis extract do not exhibit any toxic effects. The analyses carried out for the purpose of this work (TEM, SEM and AFM) showed that the obtained nanoparticles were spherical and locally agglomerated, and the agglomerates were about $40 \mathrm{~nm}$, which could affect the lack of toxicity of the obtained particles. Furthermore, silver nanoparticles initially stimulated the growth of garden cress, then inhibited it, and stimulated it again. The obtained biologically silver nanoparticles stimulated flax growth at all tested concentrations. The studies led to a conclusion that silver nitrate was the most phytotoxic solution to both flax and garden cress seeds. The prepared $\mathrm{AgNO}_{3}$ solution had an inhibitory effect at all assessed concentrations. The extract of $V$. officinalis exhibited interesting properties: Initially, it stimulated the growth of flax, and as the concentration increased, a toxic effect was observed.

Acknowledgements Research on synthesis was financed from grant for young researchers in 2016 of the Ministry of Science and Higher Education.

\section{Compliance with ethical standards}

Conflict of interest The authors declare that they have no conflict of interest.

Open Access This article is distributed under the terms of the Creative Commons Attribution 4.0 International License (http://creativeco mmons.org/licenses/by/4.0/), which permits unrestricted use, distribution, and reproduction in any medium, provided you give appropriate credit to the original author(s) and the source, provide a link to the Creative Commons license, and indicate if changes were made.

\section{References}

Ajitha B, Reddy YAK, Reddy PS (2015) Green synthesis and characterization of silver nanoparticles using Lantana camara leaf extract. Mater Sci Eng C 49:373-381

Al-Huqail AA, Hatata MM, Al-Huqail AA, Ibrahim MM (2018) Preparation, characterization of silver phyto nanoparticles and their impact on growth potential of Lupinus termis L. seedlings. Saudi J Biol Sci 25(2):313-319

Cvjetko P, Zovko M, Štefanić PP, Biba R, Tkalec M, Domijan AM, Balen B (2018) Phytotoxic effects of silver nanoparticles in tobacco plants. Environ Sci Pollut Res 25(6):5590-5602
El-Temsah YS, Joner EJ (2012) Impact of Fe and Ag nanoparticles on seed germination and differences in bioavailability during exposure in aqueous suspension and soil. Environ Toxicol 27(1):42-49

George S, Lin S, Ji Z, Thomas CR, Li L, Mecklenburg M, Hohman JN (2012) Surface defects on plate-shaped silver nanoparticles contribute to its hazard potential in a fish gill cell line and zebrafish embryos. ACS Nano 6(5):3745-3759

Gopinath K, Kumaraguru S, Bhakyaraj K, Thirumal S, Arumugam A (2016) Eco- friendly synthesis of $\mathrm{TiO}_{2}$, Au and Pt doped $\mathrm{TiO}_{2}$ nanoparticles for dye sensitized solar cell applications and evaluation of toxicity. Superlattices Microstruct 92:100-110

Gründemann C, Garcia-Käufer M, Sauer B, Stangenberg E, Könczöl M, Merfort I, Huber R (2013) Traditionally used Veronica officinalis inhibits proinflammatory mediators via the NF- $\mathrm{KB}$ signalling pathway in a human lung cell line. J Ethnopharmacol 145(1):118-126

Johari SA, Sarkheil M, Tayemeh MB, Veisi S (2018) Influence of salinity on the toxicity of silver nanoparticles (AgNPs) and silver nitrate $\left(\mathrm{AgNO}_{3}\right)$ in halophilic microalgae, Dunaliella salina. Chemosphere 209:156-162

Khosravi-Katuli K, Shabani A, Paknejad H, Imanpoor MR (2018) Comparative toxicity of silver nanoparticle and ionic silver in juvenile common carp (Cyprinus carpio): accumulation, physiology and histopathology. J Hazard Mater 359:373-381

Kumari M, Mukherjee A, Chandrasekaran N (2009) Genotoxicity of silver nanoparticles in Allium cepa. Sci Total Environ 407(19):5243-5246

Lin D, Xing B (2007) Phytotoxicity of nanoparticles: inhibition of seed germination and root growth. Environ. Poll. 150:243-250

Ma X, Geiser-Lee J, Deng Y, Kolmakov A (2010) Interactions between engineered nanoparticles (ENPs) and plants: phytotoxicity, uptake and accumulation. Sci Total Environ 408:3053-3061

Navarro E, Baun A, Behra R, Hartmann NB, Filser J, Miao AJ, Sigg L (2008) Environmental behavior and ecotoxicity of engineered nanoparticles to algae, plants, and fungi. Ecotoxicology 17(5):372-386

Ng AMC, Guo MY, Leung YH, Chan CM, Wong SW, Yung MM, Chan WK (2015) Metal oxide nanoparticles with low toxicity. J Photochem Photobiol B 151:17-24

Parida UK, Bindhani BK, Nayak P (2011) Green synthesis and characterization of gold nanoparticles using onion (Allium cepa) extract. World J Nano Sci Eng 1(04):93

Patil CD, Borase HP, Patil SV, Salunkhe RB, Salunke BK (2012) Larvicidal activity of silver nanoparticles synthesized using Pergularia daemia plant latex against Aedes aegypti and Anopheles stephensi and nontarget fish Poecillia reticulata. Parasitol Res 111:555-562

Pereira SP, Jesus F, Aguiar S, de Oliveira R, Fernandes M, Ranville J, Nogueira AJ (2018) Phytotoxicity of silver nanoparticles to Lemna minor: surface coating and exposure period-related effects. Sci Total Environ 618:1389-1399

Pittol M, Tomacheski D, Simões DN, Ribeiro VF, Santana RMC (2017) Macroscopic effects of silver nanoparticles and titanium dioxide on edible plant growth. Environ Nanotechnol Monit Manag $8: 127-133$ 
Pokhrel LR, Dubey B (2013) Evaluation of developmental responses of two crop plants exposed to silver and zinc oxide nanoparticles. Sci Total Environ 452:321-332

Raj S, Mali SC, Trivedi R (2018) Green synthesis and characterization of silver nanoparticles using Enicostemma axillare (Lam.) leaf extract. Biochem Biophys Res Commun 503(4):2814-2819

Saqib NU, Rahim M (2016) Toxicity of silver nanoparticles. Madridge J Nano Tech 1(1):1-2

Shanthi S, Jayaseelan BD, Velusamy P, Vijayakumar S, Chih CT, Vaseeharan B (2016) Biosynthesis of silver nanoparticles using a probiotic Bacillus licheniformis Dahb1 and their antibiofilm activity and toxicity effects in Ceriodaphnia cornuta. Microb Pathog 93:70-77

Stoehr LC, Gonzalez E, Stampfl A, Casals E, Duschl A, Puntes V, Oostingh GJ (2011) Shape matters: effects of silver nanospheres and wires on human alveolar epithelial cells. Particle Fibre Toxicol 8(1):36

Thuesombat P, Hannongbua S, Akasit S, Chadchawan S (2014) Effect of silver nanoparticles on rice (Oryza sativa L. cv. KDML 105) seed germination and seedling growth. Ecotoxicol Environ Saf 104:302-309

Tripathi DK, Singh S, Singh S, Srivastava PK, Singh VP, Singh S, Chauhan DK (2017) Nitric oxide alleviates silver nanoparticles (AgNps)-induced phytotoxicity in Pisum sativum seedlings. Plant Physiol Biochem 110:167-177

Zahir AA, Rahuman AA (2012) Evaluation of different extracts and synthesized silver nanoparticles from leaves of Euphorbia prostrata against Haemaphysalis bispinosa and Hippobosca maculata. Vet Parasitol 187(3):511-520 